\title{
Health Status and Personal Hygiene among Food Handlers Working at Food Establishment around a Rural Teaching Hospital in Wardha District of Maharashtra, India
}

\author{
Abhay Bhausaheb Mudey \\ Associate Professor, Department of Community Medicine \\ Jawaharlal Nehru Medical College, Sawangi (M), Wardha, Maharashtra, India \\ Tel: 91-937-318-7088 E-mail: abhaymudey@hotmail.com \\ Naveeta Kesharwani \\ Postgraduate, Department of Community Medicine \\ Jawaharlal Nehru Medical College, Sawangi (M), Wardha, Maharashtra, India \\ E-mail:dr.navitak@yahoo.com \\ Gargi Abhay Mudey \\ Postgraduate, Department of Microbiology \\ Jawaharlal Nehru Medical College, Sawangi (M), Wardha, Maharashtra, India \\ E-mail: gargimudey@hotmail.com \\ Ramchandra C. Goyal \\ Professor and Head, Department of Community Medicine \\ Jawaharlal Nehru Medical College, Sawangi (M), Wardha, Maharashtra, India \\ E-mail: drgoyal_45@rediffmail.com
}

Ajay K Dawale

Assistant Professor, Department of Community Medicine

Jawaharlal Nehru Medical College, Sawangi (M), Wardha, Maharashtra, India

Email: ajaydawale@yahoo.com

Vasant V Wagh

Professor, Department of Community Medicine

Jawaharlal Nehru Medical College, Sawangi (M), Wardha, Maharashtra, India

E-mail: drvasantwagh@yahoo.com.in

\begin{abstract}
Introduction: The chances of food contamination largely depend on the health status of food handlers $\&$ their hygiene behaviors and practices. Often these food handlers are appointed without proper health examination. The present study was conducted to assess health status of food handlers working in food establishment nearby a medical institute. Material \& methods: A cross-sectional study was conducted on randomly selected 160 food handlers of both sexes. Stool examination and nail culture was also done. Result: There was no registration of these food establishments. Most of the food handlers were young in age, mostly cooks (35.62 \%) and literate $(63.13 \%)$. Point prevalence of morbidity was 54 (33.75\%) and period prevalence $26.25 \% .21 .87 \%$ were anemic.
\end{abstract}


Microbial positivity rate for their stool \& nail culture was 97 percent. Conclusion: Registration of all food establishments should be mandatory. Pre-placement and periodical medical checkup is the key to improving health status of food handlers for better food safety.

Keywords: Food handler, Food handling, Hygiene, Health status, Bacterial infections

\section{Introduction}

Industrialization, urbanization and population growth have promoted people to migrate from rural to urban areas, forcing them to have their meals at any place at an affordable price. In urban areas, there is mushrooming of eating establishments due to increased demand.

The term food safety is increasingly being used in place of food hygiene and encompasses a whole range of issues that must be addressed for ensuring the safety of prepared food. Food hygiene probably put too much emphasis on cleanliness but food safety requires much more than a clean premises (Food Hygiene Safety). The high incidence of food borne illnesses has led to an increase in global concern about food safety (Van Tonder, 2007). Several food-borne disease outbreaks have been reported to be associated with poor personal hygiene of people handling foodstuffs.

Food borne diseases are increasing in both developed and developing countries. Diarrhoeal diseases, mostly caused by food borne microbial pathogens, are leading causes of illness and deaths in the developing countries, killing an estimated 1.9 million people annually at the global level (Schlundt J, 2004).

An estimated 76 million food borne illnesses occur annually in the United States. These food-borne illnesses result in an estimated 325,000 hospitalizations and 5000 deaths every year in the United States. The cost of the most common food borne illnesses in the United States is estimated at \$6.5-\$34.9 billion annually (Mead PS, 1999). In the past few decades, the epidemiology of food borne diseases has changed with several emerging and reemerging pathogens. Some of them may pose a low risk to most individuals, but may be life-threatening to others (Maizun Mohd Zain, 2002).

Between 1998 and 2002, an average of 1329 food borne disease outbreaks were reported to the Center for Disease Control and Prevention (CDC) each year. Approximately 52\% of these were attributed to food service establishments (Jones TF, 2006; Lynch M, 2006). During the same period, the Oregon Public Health Division reported 62 food borne outbreaks or approximately 5\% of the national total (Emilio E. DeBess, 2009). Another study conducted in Malaysia also showed that approximately $10-20 \%$ of food-borne disease outbreaks are due to contamination by the food handlers (Zain MM, 2002).

We, as the Public Health Epidemiologists along with Environmental Health Specialists are the first to respond to a food borne outbreak, and to investigate, analyze, and report any food borne disease outbreaks, including restaurant-associated illnesses. Routine surveillance underestimates the incidence of food borne gastrointestinal illness related to food consumption in restaurants by approximately 20-38 times (Evan MR, 2006; Jones TF, 2006).

Food contamination may occur at any point during its journey through production, processing, distribution, and preparation (Green L, 2005; Hennessy TW, 2004). The risk of food getting contaminated depends largely on the health status of the food handlers, their personal hygiene, knowledge and practice of food hygiene (Mead PS, 1999). Infections can also be acquired through contaminated unwashed fingers, insects, and circulation of bank notes and by wind during dry conditions (Isara AR, 2009). Contamination of food with eggs and cysts especially those sold by hawkers may also serve as a source of infection to consumers of such items (Umeche N, 1991). Therefore, food handlers i.e. any person who handles food, regardless whether he actually prepares or serves it, play an important role in the transmission and, ultimately, prevention of food borne disease (Isara AR, 2009). Information regarding food handlers' practices is key to addressing the trend of increasing food borne illnesses.

In recent years, due to changing lifestyle, breakdown of joint family system and increase in number of working women has led to consumption of ready to eat foods. The individuals may be able to satisfy their taste and nutrition needs, but pays little attention to hygiene and food safety (Santosh MJ, 2008).

It is necessary to register all types of food establishment so that supervision and monitoring of hygiene of the food as well as the food handlers can be done. There are hardly any registered food establishments existing in rural and peri-urban areas of Wardha district. There are many sporadic cases of food borne diseases reported among the consumers. This study was undertaken with the aim to evaluate the knowledge and practices of food handlers and identify gaps in education \& training of food handlers. The objectives of the study were to:

1. Assess health status of food handlers working at food establishments situated in the study area. 
2. Assess relationship between food handler's hygiene behavior and practice $\&$ their health status.

3. Assess the microbial growth patterns of food handler's stool and hand nail.

4. Know registration status of food establishments present in the study area.

\section{Methodology}

Study Design: This is a cross-sectional study conducted in a rural area of Wardha district of Central India, situated in close proximity to Acharya Vinoba Bhave Rural teaching Hospital.

Study Sample: The study was carried out between October to December 2009, amongst food handlers working in 15 food establishments located in the study area. A food handler is any person who handles food, regardless of whether he actually prepares or serves it (Isara AR, 2009). Of the 169 total food handlers working in these 15 food establishments, 160 food handlers (94.67\%) participated in the study. Those food handlers who could not be contacted even after three visits, were unwilling to give stool/nail specimen, refused to participate were excluded from the study.

Study Method: During first visit, a list of all the food handlers working in 15 establishments was prepared. During the subsequent visits, a pretested questionnaire was used to collect the demographic details of the food handlers; information related to personal hygiene, personal habits, history of illness; and registration of food establishments. The questionnaire also assessed the individual's knowledge about prevention of food borne illnesses, food hygiene and attitude towards measures for control \& prevention of food borne illnesses. An observational checklist was used to assess environmental hygiene, cleanliness of food, and food handling practices. General \& systemic examination of all of the study participants was carried out. Hand nails were examined \& samples of fingernail contents were collected from both the hands of each subject using sterile -moistened swab sticks. The participants were each handed a culture bottle and requested to bring stool sample next morning. The stool \& nail sample thus collected were immediately transported to microbiology laboratory. All the samples were cultured on Mac Conkey Agar \& Blood Agar and incubated at $37^{\circ} \mathrm{C}$ for 24 hours and the bacterial species were identified using standard procedures (Mackie, 2007).

Data collection and analysis: Information from food handlers on above mentioned variable were collected using interview technique. Findings of the nail and stool culture after microbiological examination were noted. Data on registration of food establishments were enquired from owner and verified from local health authorities of the district. Data thus collected was analyzed. The health status of the individual was co-related with the economic status. Economic status of the individual is categorized into two groups' Below Poverty Line (BPL)' \& 'Above Poverty Line (APL)'. For urban dwellers, the BPL is defined as living on less than 538.60 rupees (approximately USD \$12) per person per month, and for rural dwellers, less than 356.35 rupees per person per month (approximately USD \$7.50). Those who have earning above this amount were considered as APL (Tenth five-year plan, 2002-2007).

\section{Results}

There was no registration of any of these 15 food establishments of the 160 food handlers, $54.37 \%$ were below 30 years of age, whereas $3.75 \%$ were children less than 10 years of age. Majority of food handlers were males $(69.38 \%)$ and from rural areas $(66.87 \%) .46 .25 \%$ were helpers while $35.62 \%$ were cooks.

$36.87 \%$ participants were illiterate while $25.62 \%$ were educated up to secondary school. The percentage of participants who were below poverty line was $33.75 \%$.

$58(36.25 \%)$ of the food handlers were free from any of the common addictions. However the percentage of food handlers with one or more addictions is high. $39(24.37 \%)$ were smokers, $44(27.50 \%)$ consumed alcohol daily, $30(18.75 \%)$ were in the habit of chewing tobacco and $32(20 \%)$ habituated to pan chewing. Some of the food handlers were habituated to more than one habit. $(32.50 \%)$ was mostly found to be both smokers as well as alcoholics.

As mention in Table 2, majority of the participants (73.74\%) were having clean nails and were cutting their nails satisfactorily i.e. at least once a week. $49.38 \%$ were washing hands with soap and water after using the toilet. The kitchen surface area was found to be clean in $73.13 \%$ of the food establishments and was being cleaned by soap \& detergents $(61.87 \%)$.

When health status of study group was assessed it was found that $21.87 \%$ were suffering from anemia, dental carries $(10 \%)$, halitosis $(10 \%)$ and scabies $(5.62 \%)$. Point prevalence of morbidity was $33.75 \%$ and period prevalence in three months period was found to be $26.25 \%$. 42(26.25\%) of food handlers, reported some illness in the past three months. (Table No. 3). 
Table No. 4 shows that Klebsiella was found in 56(35\%) \& Pseudomonas in 4 (2.50\%) of the stool cultures, and Staphylococcus in 91(56.87\%), E-coli in 28(17.5\%), and Klebsiella in 35(21.87\%) of the nail cultures.

When association between education and their personal hygiene was assessed, it was found that amongst the illiterate group, only $13.79 \%$ were cleaning cloths, $14.28 \%$ were using overhead cap, $5.71 \%$ kept their hair neat and tidy, $7.14 \%$ had clean nails, and $16.66 \%$ were using footwear. In comparison the percentage of literates wearing clean clothes was $(31.03 \%)$, wearing cap $(28.57 \%)$, neat and tidy hair $(25.71 \%)$, clean nails $(25 \%)$ and footwear $(50 \%)$. This shows that literacy level of food handlers is inversely proportional to their personal hygiene practices. (Figure I)

Food handlers who belongs to Below Poverty Line group were found suffering mainly from morbid conditions like Anaemia (59.25\%), halitosis (11.11\%), scabies (9.25\%), and Phyrnoderma (3.75\%). Tuberculosis, leprosy and skin diseases together accounted for $12.96 \%$. Comparatively the Above Poverty Line group suffered mainly from diseases like Hypertension and Diabetes (3.77\%) and Dental Carries (11.32\%). (Figure II)

\section{Discussion}

Despite continuing progress made in food quality and safety, food borne disease outbreaks continue to be reported in the literature. The most frequently identified factors contributing to the outbreaks are contaminated raw foods/ ingredients, and poor personal hygiene by persons who handle foods (Report of the FDA retail food programs, 2000).

The study reveals that maximum number (54.37\%) of food handlers were below 30 years of age but unfortunately $3.75 \%$ were small children below the age of 10 years. In a similar study by Udgiri RekhaS, Masali KA (2007) they found $73.2 \%$ of respondents were below 30 years of age and only $9(2.72 \%)$ respondents were above 50 years whereas Gupta and Ketkar (1981) from Nagpur in their study on food handlers observed that $22.3 \%$ of them were below 25 years of age. It is also seen that a majority $(69.38 \%)$ of food handlers were males in the present study. Maximum number (46.25\%) were helpers and majority (66.87\%) of food handlers were from rural areas while 29 (18.13\%) were from the slums. In a study by Isara AR and Isah $\boldsymbol{E C ( 2 0 0 9 )}$ they found $65.1 \%$ were females while another study by Maizun Mohd Zain and Nyi Nyi Naing (2002) found 69.5\% of the food handlers were females.

59 (36.87\%) food handlers were found illiterate in the present which differed markedly from the study by Isara $\boldsymbol{A R}$ and Isah $\boldsymbol{E C}$ (2009), wherein they found $98 \%$ of the respondents were having formal education. The lower literacy rate in the present study may be due to the fact that majority of food handlers were migrants from states like Madhya Pradesh, Bihar and Uttar Pradesh where the literacy rates are relatively lower.

Gupta and Ketkar (1981) reported that 50\% of the food handlers were habituated to chewing pan and $40.1 \%$ to chewing tobacco. These findings varied from the present study, where 39(24.37\%) were smokers, $44(27.50 \%)$ consumed alcohol daily, 30(18.75\%) were in the habit of chewing tobacco and 32(20\%) habituated to pan chewing. Some of the food handlers were habituated to more than one habit. $(32.50 \%)$ was mostly found to be both smokers as well as alcoholics. 58(36.25\%) of the food handlers were free from any of the addictions.

Food handlers who belongs to below poverty line group were found suffering from majority of the morbid conditions like anemia, halitosis, scabies \& other skin diseases, phyrnoderma, tuberculosis, leprosy as compared to those above poverty line. However Hypertension, Diabetes and Dental Carries were more common amongst the individuals who were above poverty line. (Figure II). For urban dwellers, below poverty line is defined as living on less than 538.60 rupees (approximately USD \$12) per person per month, and for rural dwellers, less than 356.35 rupees per person per month (approximately USD \$7.50). (Schlundt J, 2004)

$42(26.25 \%)$ of food handlers, reported some illness in the past three months. The morbidity suffered by the participants is depicted in table no. 3 in order of magnitude. The past history was restricted to 3 months to facilitate better recall. Rathore AS (1993) observed that $25.33 \%$ of food handlers suffered one or the other illness in the past 6 months. Of the total 160 food-handlers, 54(33.75\%) were currently suffering from some or the other disease. Anemia was found in 35(21.87\%) individuals. The high level of morbidity in food handlers could probably be due to poor environmental conditions, poor personal hygiene and low socio-economic status. Chitnis (1986) who had reported $74.13 \%$ overall morbidity, found that anemia $(22.13 \%)$ was the most frequently seen morbid conditions.

When stool culture was examined, Klebsiella was found in 56(35\%) food handlers, Pseudomonas in 4(2.50\%), beta Streptococcus and Proteus (1.87 \& 1.25\% respectively) and Salmonella in 5(3.12\%). We found Staphylococcus in 91(56.87\%), E-coli in 28(17.5\%) and Klebsiella in 35(21.87\%) in nail cultures. In a study by Gashaw Andargie and et al they isolated several species of bacteria, including S. aureus (16.5\%), and intestinal bacterial species, such as Klebsiella (5.5\%), Enterobacter (0.8\%), E. coli (3.1\%) from their fingernail contents (Gashaw Andargie, 2008). Mohan V (2001) observed the overall prevalence of intestinal parasite infestation to be 
14\% whereas in a study by $\boldsymbol{O A}$ Idowu and SA Rowland (2006) 97\% of the food vendors were infected with one or more faeco-orally transmissible parasites. Such a high prevalence of intestinal parasites is largely due to poor personal hygiene practices and environmental sanitation, lack of supply of safe water, poverty, ignorance of health-promotion practices, and impoverished health services.

Washing of hand with only water (without using soap) after using the toilet was practiced by $81(50.62 \%)$ whereas frequency of cutting nails is less or nil in $26.25 \%$ of the food handlers. Gashaw Andargie and et al reported that $11 \%$ of the food-handlers did not practice hand-washing after using the toilet, this shows that there is a need to give more emphasis on personal hygiene, self care $\&$ related practices of food handlers.

\section{Conclusions}

The health status and the level of personal hygiene of the food handlers in the eating establishments were found to be unsatisfactory. The cooks and suppliers who handled food were not maintaining a satisfactory personal hygiene, thereby increasing the risk of food contamination considerably. Good personal hygiene is also expected among the cleaning and dish washing staff. Food hygiene can be best promoted by educating the food handlers about personal hygiene. The findings highlight the importance of food hygiene education among food handlers; to inculcate the practices of good personal hygiene.

Although most of the workers in the organized sectors are covered under the Employee's State Insurance scheme and are entitled to medical and other benefits, it is not the case with the unorganized sectors, and small food establishments. Daily inspections of the workers with regard to their health and hygiene, Periodic medical examination along with necessary treatment such as de-worming should be done. Training in hygiene and sanitation for all employees working in food establishments is an essential step towards ensuring food safety.

\section{References}

Chitnis UKB. (1986). An evaluation of health status of workers in eating establishments in Pune Cantonment. Medical Journal of Armed Forces, 2: 34-5.

Emilio E. DeBess, Eric Pippert, Frederick J. Angulo and Paul R. Cieslak. (2009). Food handler assessment in Oregon. FOODBORNE PATHOGENS AND DISEASE, Volume 6: Number 3.

Evan MR, Sarvotham T and et al. (2006). Domestic and travel-related food borne gastrointestinal illness in a population health survey. Epidemiological Infections, 134: 686-693.

Food Hygiene Safety. [Online] Available: www.articlesbase.com, Mar 27, 2009.

Gashaw Andargie, Afework Kassu, Feleke Moges, Moges Tiruneh and Kahsay Huruy. (2008). Prevalence of bacteria and intestinal parasites among food handlers in Gondar Town, Northwest Ethiopia. Journal of health, population and nutrition, Volume 26, Number 4, December, pp 451-455

Green L, Selman C and et al. (2005). Food service workers self reported food preparation practices: An EHS-Net study. International Journal of Hygiene Environmental health, 208: 27-35.

Gupta SC, Ketkar YA. (1981). Prevalence of Intestinal Parasites in food handlers. Indian Medical Gazzete, 15(8): 295-8.

Hennessy TW, Cheng LH and et al. (2004). Egg consumption is the principle risk factor for sporadic Salmonella serotype Heidelberg infections: A case-control study in food net sites. Clinical infectious diseases, Volume 38 (3): 237-243.

Isara AR, Isah EC. (2009). Knowledge and practice of food hygine and safety among food handlers in fast food restaurants in Benin City, Edo state, Niger. Postgraduate Medical Journal, September, 16(3), 207-12.

Jones TF and Angulo FJ. (2006). Eating in restaurants: A risk factor for food borne disease? Clinical Infectious Diseases, Volume 43, 1324-1328.

Lynch M, Painter J. and et al. (2006). Surveillance for food borne disease outbreaks-United States: 1998-2002. MMWR Surveillance Summ, Volume 55, 1-42.

Mackie \& Mc Cartney. (2007). Practical Medical Microbiology. 14th Edition.

Maizun Mohd Zain and Nyi Nyi Naing. (2002). Socio-demographic characteristics of food handlers and their knowledge, attitude and practice towards food sanitation: A Preliminary report South-East Asian Journal of tropical Med Public Health, Volume 33, Number 2, June, pp 410-417.

Mead PS, Slutsker L and et al. (1999). Food related illness and death in the United States. Emerging Infectious Diseases, Volume 5, pp 607-625. 
Mohan V. (2001). An evaluation of health status of food handlers of eating establishments in various educational and health institution in Amritsar city. Indian Journal of Community Medicine, 26, 80-5.

OA Idowu and SA Rowland. (2006). Oral fecal parasites and personal hygiene of food handlers in Abeokuta, Nigeria. African Health Science, September, 6(3): 160-164.

Rathore AS. (1993). An evaluation of health status of food handlers and sanitary status of messes, of training establishments in Karnataka. Indian Journal of Community Medicine, Jan-March, 18(1): 21-5.

Santosh MJ, Nogueira JR, Patarata L. (2008). Knowledge levels of food handlers in Portuguese School canteens and their self-reported behaviours towards food safety. International Journal of Environmental Health Research, December, Volume 18(6), pp 387-401.

Schlundt J, Toyofuku H, Jansen J, Herbst SA. (2004). Emerging food-borne zoonoses. Rev science Tech, Volume 23, pp 513-515.

Tenth five-year plan. (2002-2007). Survey Report.

Udgiri Rekha S, Masali KA. (2007). A study on the health status of food handlers employed in food establishments in Bijapur city. Indian Journal of Community Medicine, Volume 32, Issue 2, Page 131-132.

Umeche N. (1991). Parasite ova and cysts in fruits in Calabar, Nigeria. The Nigeria Journal of Parasitology, 12:85-87.

Van Tonder \& et al. (2007). The personal and general hygiene practices of food handlers in the delicatessen sections of retail outlets in South Africa. (International Perspectives) (Report). Journal of Environmental Health, November 1.

Zain MM, Naing NN. (2002). Socio-demographic characteristics of food handlers and their knowledge, attitude and practice towards food sanitation. A preliminary report: South-East Asian Journal of Tropical Med Public health, Volume 33(2), pp 410-417.

Table 1. Distribution of food handlers as per their socio-economic \& demographic characteristic at Wardha 2009

\begin{tabular}{|c|c|c|c|}
\hline \multicolumn{2}{|c|}{ Socio-demographic Characters } & Number & $\%$ \\
\hline \multirow{4}{*}{$\begin{array}{l}\text { Age } \\
\mathrm{N}=160\end{array}$} & $<10$ years & 06 & 03.75 \\
\hline & $10-29$ years & 81 & 50.62 \\
\hline & $30-49$ years & 59 & 36.87 \\
\hline & $>50$ years & 14 & 08.76 \\
\hline \multirow{2}{*}{$\begin{array}{l}\text { Sex } \\
N=160\end{array}$} & Male & 111 & 69.38 \\
\hline & Female & 49 & 30.62 \\
\hline \multirow{3}{*}{$\begin{array}{l}\text { Occupation } \\
\mathrm{N}=160\end{array}$} & Cook & 57 & 35.62 \\
\hline & Helper & 74 & 46.26 \\
\hline & Waiter & 29 & 18.12 \\
\hline \multirow{3}{*}{$\begin{array}{l}\text { Residence } \\
\mathrm{N}=160\end{array}$} & Rural & 107 & 66.87 \\
\hline & Urban & 24 & 15.00 \\
\hline & Slum & 29 & 18.13 \\
\hline \multirow{5}{*}{$\begin{array}{l}\text { Education } \\
\mathrm{N}=160\end{array}$} & Illiterate & 59 & 36.87 \\
\hline & Primary & 17 & 10.62 \\
\hline & Secondary & 24 & 15.00 \\
\hline & High-school & 42 & 26.25 \\
\hline & Above High-school & 18 & 11.26 \\
\hline \multirow{2}{*}{$\begin{array}{l}\text { Income Group } \\
\mathrm{N}=160\end{array}$} & $\mathrm{BPL} \dagger$ & 54 & 33.75 \\
\hline & APL $\$$ & 106 & 66.25 \\
\hline
\end{tabular}

$\dagger$ †PL -Below poverty line, $\quad$ \$PL- Above poverty line $\quad \mathrm{N}=$ Number of respondents 
Table 2. Habits \& personal hygiene practices of food handlers at working in food establishment, Wardha 2009

\begin{tabular}{|c|c|c|c|}
\hline \multicolumn{2}{|c|}{ Practices of food handlers } & \multirow{2}{*}{$\begin{array}{c}\text { Total no. } \\
39\end{array}$} & \multirow{2}{*}{$\begin{array}{c}\text { Percentages } \\
24.37\end{array}$} \\
\hline \multirow{6}{*}{$\begin{array}{c}\text { Habits } \\
\text { and } \\
\text { addictions* }\end{array}$} & Smokers & & \\
\hline & Consuming alcohol & 44 & 27.50 \\
\hline & Chewing tobacco & 30 & 18.75 \\
\hline & Betal chewing & 32 & 20.00 \\
\hline & Mixed/double habits & 52 & 32.50 \\
\hline & No addiction & 58 & 36.25 \\
\hline \multirow{4}{*}{$\begin{array}{l}\text { Frequency } \\
\text { of } \\
\text { cutting nails }\end{array}$} & 2 times in a week & 51 & 31.87 \\
\hline & 1 time in a week & 67 & 41.87 \\
\hline & 1 time in 2 week & 36 & 22.51 \\
\hline & Need not cut & 06 & 03.75 \\
\hline \multirow{2}{*}{$\begin{array}{l}\text { Washing of hand after } \\
\text { coming from toilet }\end{array}$} & With water & 81 & 50.62 \\
\hline & With soap & 79 & 49.38 \\
\hline \multirow{3}{*}{ No. of time working area is } & 1 time & 25 & 15.62 \\
\hline & 2 time & 117 & 73.13 \\
\hline & 3 time & 18 & 11.25 \\
\hline \multirow{2}{*}{ Cleansing material } & Soap / detergent & 99 & 61.87 \\
\hline & Only water & 61 & 38.13 \\
\hline \multirow{6}{*}{$\begin{array}{l}\text { Personal hygiene } \\
\text { of } \\
\text { food handlers* }\end{array}$} & Use of separate cloth & 14 & 08.75 \\
\hline & Tidy cloth & 58 & 36.25 \\
\hline & Use of cap & 14 & 08.75 \\
\hline & Tidy hair & 70 & 43.75 \\
\hline & Clean nails & 56 & 35.00 \\
\hline & Use of footwear & 06 & 03.75 \\
\hline
\end{tabular}

* Multiple response answers 
Table 3. Health status of food handlers

\begin{tabular}{|c|c|c|c|}
\hline \multicolumn{2}{|c|}{ Health Status among food handlers } & Number & Percentages \\
\hline \multirow{10}{*}{ Morbidities* } & Anemia & 35 & 21.87 \\
\hline & Dental caries & 16 & 10.00 \\
\hline & Halitosis & 16 & 10.00 \\
\hline & Phrenoderma & 03 & 01.87 \\
\hline & Scabies & 09 & 05.62 \\
\hline & ARI \& Diarrhea & 04 & 02.50 \\
\hline & Leprosy & 01 & 00.62 \\
\hline & $\mathrm{TB}$ & 05 & 03.12 \\
\hline & HT & 04 & 02.50 \\
\hline & $\mathrm{DM}$ & 02 & 01.25 \\
\hline \multirow{2}{*}{ Total morbid subjects } & During study & 54 & 33.75 \\
\hline & During last 3 months & 42 & 26.25 \\
\hline
\end{tabular}

* Multiple response answers

Table 4. Stool \& nail culture of food handlers $(n=160)$

\begin{tabular}{|l|l|c|c|}
\hline \multicolumn{2}{|c|}{ Culture of food handlers } & No of food handlers & Percentages \\
\hline \multirow{4}{*}{ Nail culture } & Staphylococcus & 91 & 56.87 \\
\cline { 2 - 4 } & E Coli & 28 & 17.50 \\
\cline { 2 - 4 } & Klebsiella & 35 & 21.87 \\
\cline { 2 - 4 } & No organism & 06 & 03.76 \\
\hline \multirow{5}{*}{ Stool culture } & E Coli & 92 & 57.50 \\
\cline { 2 - 4 } & Klebsiella & 56 & 35.00 \\
\cline { 2 - 4 } & Pseudomonas & 04 & 02.50 \\
\cline { 2 - 4 } & Streptococcus & 03 & 01.87 \\
\cline { 2 - 4 } & Proteus & 02 & 01.25 \\
\cline { 2 - 4 } & Salmonella & 05 & 03.12 \\
\cline { 2 - 4 } & Shigella & 04 & 02.50 \\
\cline { 2 - 4 } & No organism & 05 & 03.12 \\
\hline
\end{tabular}




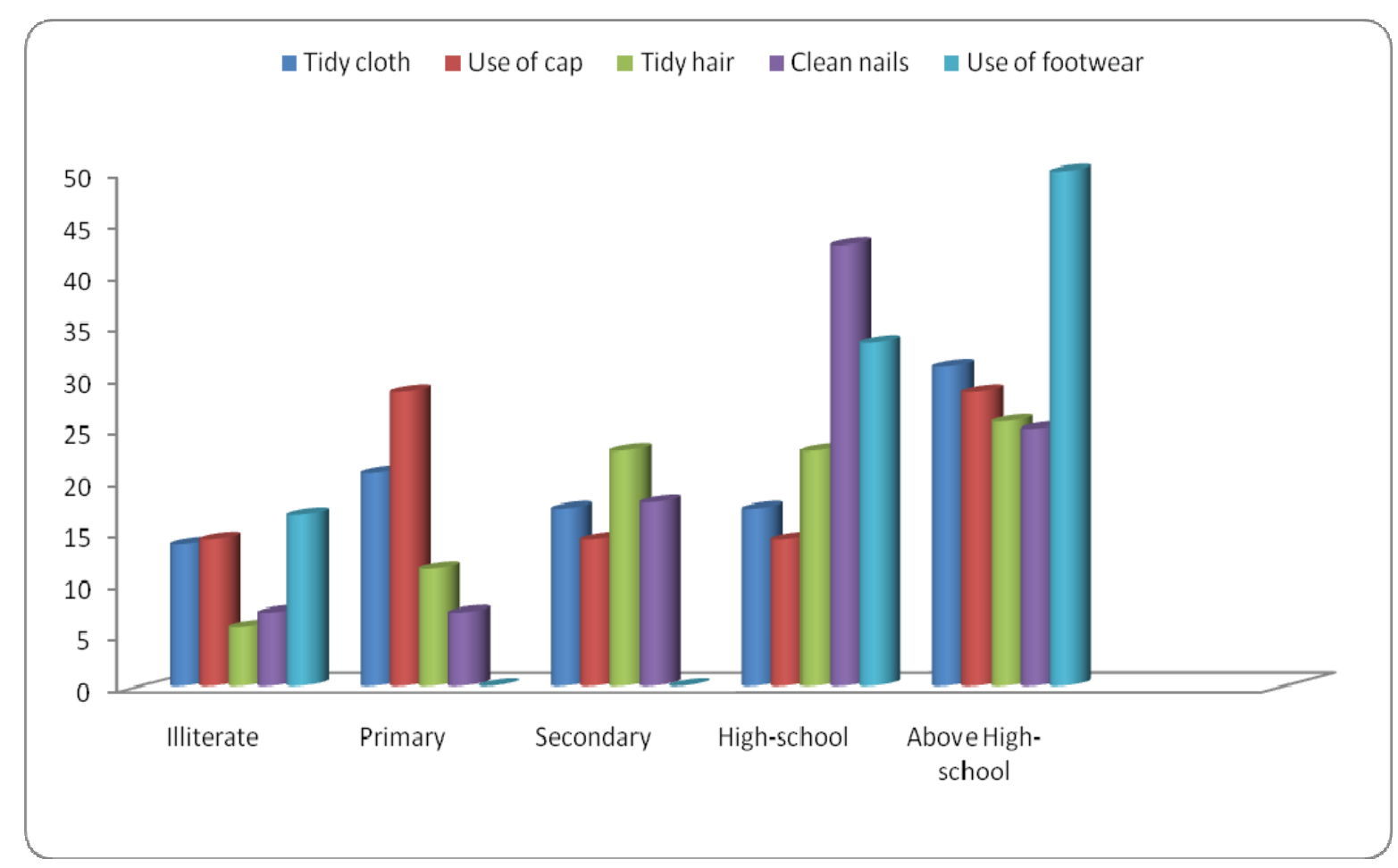

Figure 1. Association between education of food handlers and their personal hygiene

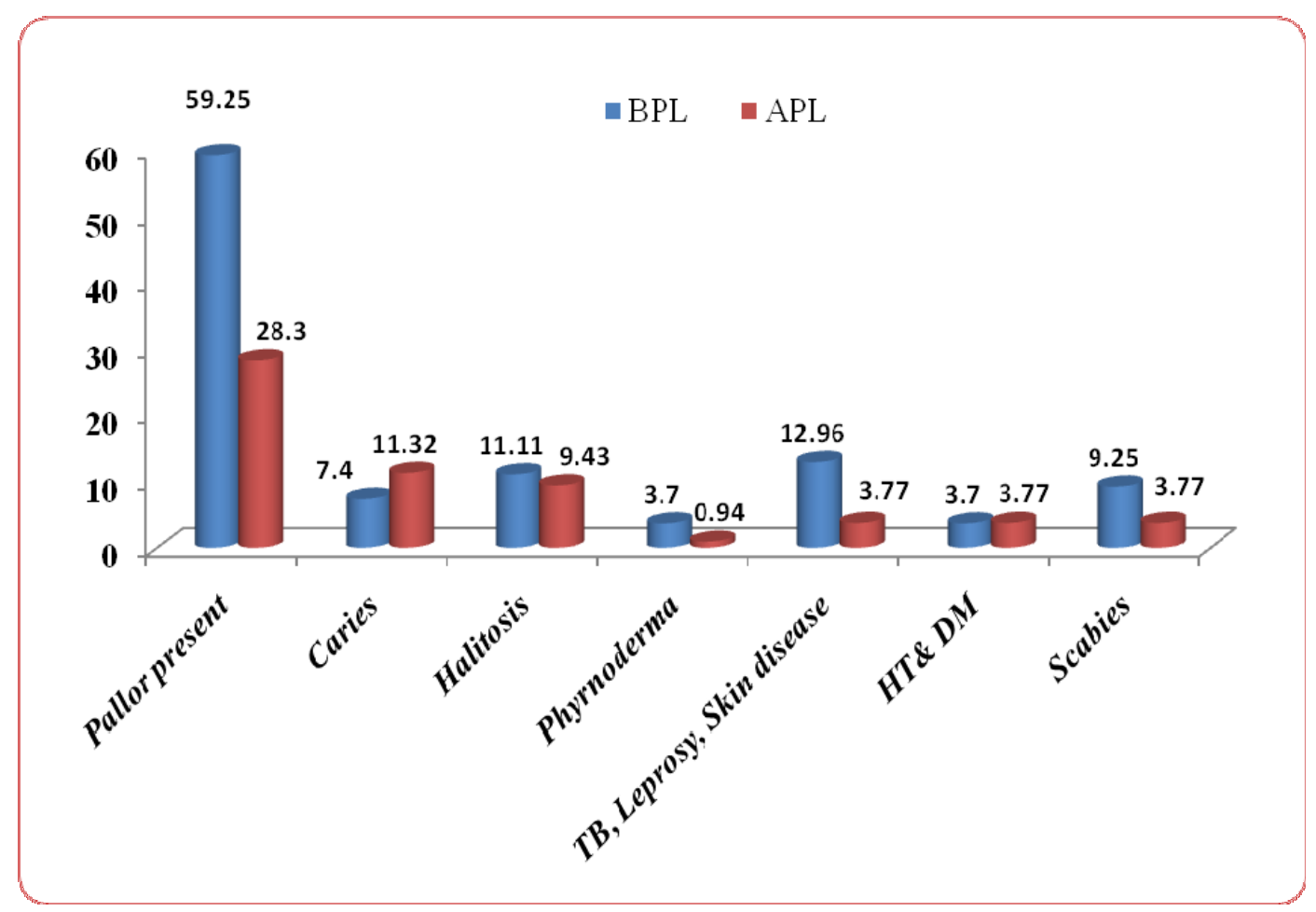

Figure 2. Association between income group and morbid conditions of food handlers 